\title{
Medication cost problems among chronically ill adults in the US: did the financial crisis make a bad situation even worse?
}

This article was published in the following Dove Press journal:

Patient Preference and Adherence

I8 April 201 I

Number of times this article has been viewed

\author{
John D Piette' \\ Ann Marie Rosland' \\ Maria J Silveira' \\ Rodney Hayward' \\ Colleen A McHorney ${ }^{2}$
}

'Ann Arbor VA Healthcare System, Ann Arbor, MI, USA; ${ }^{2}$ US Outcomes Research, Merck and Co, Inc, North Wales, PA, USA
Correspondence: John D Piette Department of Internal Medicine, University of Michigan, $300 \mathrm{~N}$ Ingalls Building, Room 7EI0, Ann Arbor, MI 48I09-5429, USA

$\mathrm{Tel}+\mathrm{I} 7349364787$

Fax +I 7349368944

Email jpiette@umich.edu
Abstract: A national internet survey was conducted between March and April 2009 among 27,302 US participants in the Harris Interactive Chronic Illness Panel. Respondents reported behaviors related to cost-related medication non-adherence (CRN) and the impacts of medication costs on other aspects of their daily lives. Among respondents aged 40-64 and looking for work, $66 \%$ reported CRN in 2008 , and $41 \%$ did not fill a prescription due to cost pressures. More than half of respondents aged 40-64 and nearly two-thirds of those in this group who were looking for work or disabled reported other impacts of medication costs, such as cutting back on basic needs or increasing credit card debt. More than one-third of respondents aged $65+$ who were working or looking for work reported CRN. Regardless of age or employment status, roughly half of respondents reporting medication cost hardship said that these problems had become more frequent in 2008 than before the economic recession. These data show that many chronically ill patients, particularly those looking for work or disabled, reported greater medication cost problems since the economic crisis began. Given links between CRN and worse health, the financial downturn may have had significant health consequences for adults with chronic illness.

Keywords: medication adherence, cost-of-care, access to care, chronic disease

\section{Introduction}

In 2008, the American economy entered one of the deepest recessions since World War II. ${ }^{1}$ According to the Bureau of Labor Statistics, unemployment rates were roughly constant at an average of $4.7 \%$ throughout 2007 but increased to $7.2 \%$ by the end of $2008 .^{2}$ Financial markets were hit hard, with the Dow experiencing a $32 \%$ decline between the beginning of 2008 and the year's end. ${ }^{3}$ Home foreclosures increased $40 \%$ between 2007 and 2008, and personal bankruptcies increased by more than $31 \%$, with an additional quarter of a million consumers filing in 2008 relative to the year before. ${ }^{4}$

For chronically ill patients, the financial upheaval was experienced in the context of an ongoing crisis in American healthcare with many Americans struggling to afford their prescription medications. Studies from the early to mid-2000s found that as many as one-third of older adults reported taking less medication than prescribed due to cost pressures. $^{5-7}$ In addition to failing to fill prescriptions or taking less than prescribed to make their treatments last longer, some patients reported cutting back on basic needs in order to pay for their prescription drugs. ${ }^{8,9}$ The negative health implications of costrelated non-adherence (CRN) - including rehospitalization, emergency room use, and cardiovascular events - have been well documented by studies using administrative data and large national surveys. ${ }^{10-14}$ Patients with chronic illnesses are particularly at risk for CRN and poor health outcomes as a result. ${ }^{15}$ 
The Medicare Modernization Act Prescription Drug Benefit (Part D) was designed to address escalating medication-cost problems among Medicare enrollees. In a study one year before the benefit took effect, Soumerai and colleagues found that $12.6 \%$ of elderly Medicare enrollees reported some CRN and that rates were as high as $29.4 \%$ among non-elderly disabled enrollees. ${ }^{5}$ Enrollees in poor health or who had multiple chronic conditions were at the highest risk for CRN. Using data from the years immediately following the implementation of Part D (2006-2007), researchers have reported moderate decreases in CRN and increased spending on prescription drugs. ${ }^{9}, 16$ While these changes may translate into better health outcomes for some patients, those with more chronic illnesses have shown fewer benefits. ${ }^{916}$ The limited impact of Part D may reflect the large numbers of eligible patients who fail to enroll $1^{17,18}$ as well as the sizable number of enrollees who reach the "doughnut hole" (19\% of all Part D enrollees and as many as $49 \%$ of patients taking medication for stroke or myocardial infarction ${ }^{19}$ ), leaving them uncovered for their prescriptionmedication expenses. In an era in which home prices lost on average $30 \%$ of their value and the nation's collective net worth decreased more than three trillion dollars, ${ }^{20}$ the ability of older adults to continue affording their medications with or without Part D covered should be reexamined.

While older adults have a higher prevalence of chronic illnesses and unique medication use needs, a review of the literature reported higher rates of $\mathrm{CRN}$ among younger patients in 11 out of 13 studies identified. ${ }^{15}$ Because most "working age" individuals are ineligible for the Part D benefit, the impact on this group of the recent economic crisis may have been particularly severe. As such, understanding the rates of CRN among adults under 65 years of age and comparing disparities between those rates and rates among individuals eligible for Part D represent important goals for research on ways to improve medication coverage and prevent costly health crises.

To examine how the economic downturn impacted costrelated medication problems, we analyzed a nation survey of a diverse panel including more than 27,000 chronically ill older adults. We were particularly interested in understanding: 1) recent prevalences of cost-related medication underuse and other financial hardships due to medication-cost pressures; 2) whether patients' medication-cost problems worsened since the beginning of the economic recession relative to the year before; and 3) whether Part D coverage helped buffer those aged 65 and older from medication-cost hardships.

\section{Methods}

\section{Study population}

Study participants were part of the Harris Interactive Chronic Illness Panel (CIP), which is a national, internet-based panel of adults with chronic diseases. CIP participants are recruited through a number of avenues including postal mail invitations, TV advertisements, telephone recruitment for under-represented populations, targeted email solicitations, and text banner placement on partners' websites, eg, social media sites, news sites, search engine sites, and community portals. Panel recruitment and maintenance efforts are focused on maintaining a representative sample of the general population as well as identifying and reaching underrepresented and hard-to-reach groups.

In February and March of 2009, randomly selected members of the CIP were sent an e-mail invitation to participate in the survey. Panel members were eligible for participation if they were aged 40 and older, resided in the US, and reported one of six chronic diseases prevalent among US adults: hypertension, hyperlipidemia, diabetes, asthma, osteoporosis, and depression. The study was approved by the George Mason University Institutional Review Board.

Of the 51,774 CIP panel members who were US residents aged 40 or older and completed the chronic-disease screener, 27,302 persons with chronic diseases (53\%) completed the survey. CIP members who were successfully contacted were more likely to be aged 50 or older, male, white, college educated, and of higher income than unsuccessfully contacted members (all $P<0.0001)$.

\section{Measures}

Participants responded to a series of questions regarding strategies adults use to reduce medication use in order to minimize out-of-pocket costs, such as a delay in filling a prescription or stopping a prescription all together. Respondents also reported other financial impacts of prescription-medication expenditures, such as cutting-back on spending for basic necessities or increasing credit card debt. Items were adapted based on a review of measures in prior surveys conducted by the Medicare Current Beneficiary Survey, the AARP, the Kaiser Family Foundation, and other groups. ${ }^{7,21-30}$ The timing of each medication-cost impact was emphasized using the question stem: "In 2008, because of the cost of all of [your] prescription medications ..." Each cost-reducing strategy was measured using a five-point scale ranging from "Yes, very often" to "No, never". In subsequent questions, respondents who reported a given impact of medication-cost pressures were asked whether the problem was experienced "more frequently 
in 2008 than in 2007", "about the same in 2008 as in 2007", or "less frequently in 2008 than in 2007". In addition to reporting data on individual CRN behaviors, summary measures were created for any cost-related non-adherence and any other financial impact of medication costs.

Additional data about the sociodemographic characteristics of respondents was available from information they provided as enrollees in the CIP. These included respondents' race/ethnicity (collected as white non-Hispanic, Hispanic, black non-Hispanic, and other race/ethnicity), educational attainment, and income. Household income was reported using 11 categories ranging from $<$ US $\$ 15,000$ per year to $\$ 250,000$ or more. Respondents reported their employment status in the following categories: employed full-time, employed parttime, unemployed and looking for work, unemployed and not looking for work, disabled and unable to work, full time student, or full time homemaker. For the analyses presented here, participants were considered "unemployed and not looking for work" if they reported being a full-time student (and did not report being employed full- or part-time) or they reported being a full-time homemaker. For respondents aged $65+$, those not reporting that they were employed (full- or parttime) or looking for work, were categorized as retired.

\section{Analysis}

All analyses were conducted using sampling weights that allowed estimates to be generalized to the US population of chronically ill adults over the age of 40. Cross-tabulations and chi-square tests were used to examine variation in respondents' sociodemographic and clinical characteristics across age groups (40-64 versus 65+). The prevalence of each potential medication-cost problem in 2008 was examined. Finally, the proportion of respondents reporting that a given problem occurred more frequently in 2008 than in 2007 was examined. Prevalences of each problem were estimated for the overall sample and within age groups (40-64 versus $65+)$. The sample was then stratified by age and variations in medicationcost problems were examined across employment categories. All proportions were adjusted for potential confounders using logistic regression models with post-test probability estimation. Specifically, logistic models were used to examine variation across groups in respondents' adjusted probability of experiencing each medication-cost problem in 2008. A second series of models was then executed to examine variation across age and employment categories in the probability of experiencing medication-cost problems that were more frequent in 2008 than in 2007. For age-and sex-adjusted analyses, multivariable logistic regression models were used to generate predicted probabilities (using population means for the age and sex variables) and to test for statistically significant differences for each medication-related problem. We set "employed" as the reference group for pair-wise significance testing of employment groups for those younger than 65 years and "retired" as the employment reference group for those 65 or older. All analyses were conducted with Stata 11.0 (College Station, TX) and survey weights were used to make all results as representative as possible to the US population with chronic illnesses. Auxiliary analyses also controlled for race and Hispanic ethnicity, educational attainment, and number of chronic diseases. Because those models did not show meaningful differences compared to the more parsimonious age/sex-adjusted models, the results of the age/sex-adjusted models are presented here.

\section{Results Sample description}

Just over one-third (35\%) of the overall sample of 27,302 respondents was aged 65 or older; $93.2 \%$ was white nonHispanic, $2.3 \%$ was black non-Hispanic, $0.7 \%$ was Hispanic, and the remaining $3.8 \%$ reported "other" race/ethnicity. Despite the slightly higher contact rates among male CIP participants, just over one half of the analytic sample (53\%) was female. Survey respondents included 13,606 individuals who were employed either full-time, part-time or selfemployed. An additional 838 respondents were out of work and looking for a job; 2,251 were either stay-at-home spouses, students, or other respondents who were unemployed but not looking for work; 10,348 were retired; and 259 reported that they were disabled and unable to work (Table 1). Respondents aged 40-64 were more likely to be employed and have fewer chronic conditions, while those age 65 or older were more likely to be retired and report less income.

The majority of respondents in each employment group were white, and the proportion that was female ranged from $48 \%$ among employed respondents to $78 \%$ among those who were unemployed but not looking for work. Annual household incomes varied around the 2007 national median of $\$ 50,000,{ }^{31}$ with $32 \%$ of employed respondents reporting incomes lower than $\$ 50,000$, and $83 \%$ of those who were disabled and unable to work reporting incomes below that level. The proportion of respondents reporting fair or poor health status ranged from $24 \%$ among employed individuals to $71 \%$ among those reporting that they were disabled and unable to work. Participants who reported that they were unemployed and looking for a job were, on average, 57 years of age, had no college degree $(70 \%)$, were female $(56 \%)$, 
Table I Sample description

\begin{tabular}{llll}
\hline & & Age & \\
\cline { 3 - 4 } & & $\mathbf{4 0 - 6 4}$ & $\mathbf{6 5 +}$ \\
\hline $\mathrm{N}$ & 27,302 & 17,787 & $9,5 \mathrm{I}$ \\
Employment status & & & \\
$\quad$ Employed & 13,606 & 64.4 & 22.3 \\
Unemployed & & & \\
Not looking & 838 & 4.1 & 4.1 \\
Retired & 2,251 & 12.4 & $\mathrm{n} / \mathrm{a}$ \\
Disabled and unable to work & 10,348 & 17.3 & 76.5 \\
Female & 259 & 1.8 & $\mathrm{n} / \mathrm{a}$ \\
Race & 14,572 & 53.7 & 58.1 \\
White & & & \\
Black & 25,437 & 88.3 & 96.0 \\
Hispanic & 616 & 6.1 & 2.0 \\
Other & 202 & 2.4 & 1.0 \\
No college degree & 1,047 & 3.2 & 1.2 \\
Annual income $<\$ 50,000$ & 15,572 & 65.0 & 71.9 \\
Fair/poor health & 13,067 & 42.6 & 57.7 \\
Number of chronic conditions & 9,427 & 34.2 & 26.8 \\
I & & & \\
2-3 & 7,298 & 34.8 & 24.2 \\
4+ & 15,746 & 53.5 & 64.0 \\
\hline Notes: Percentas within age groups & 4,258 & 11.7 & 11.8 \\
\hline
\end{tabular}

Notes: Percentages within age groups were calculated using sampling weights to estimate proportions within the US non-institutionalized population aged 40 and older. All differences between age groups were statistically significant $(P<0.00 \mathrm{I})$. a Unemployed and looking for work.

had incomes $<\$ 50,000(69 \%)$, and a large proportion $(41 \%)$ reported fair or poor health status.

\section{Cost-related non-adherence and medication financial hardships by age}

Overall, 44\% of respondents reported some form of CRN in 2008 , and $51 \%$ reported other financial hardships associated with their prescription-drug costs (Table 2). One-third (34\%) of respondents reported that they delayed filling a prescription in 2008 because they could not afford it, and 34\% reported they split or cut pills or took fewer than prescribed in order to make the prescription last longer. Almost one quarter (24\%) reported that they did not fill a prescription at all due to cost pressures. Medication-cost problems were consistently more common among respondents less than 65 years of age (all $P<0.001)$.

For each medication-cost problem, only $2 \%-3 \%$ of respondents reported experiencing the problem less frequently in 2008 than in 2007. In contrast, roughly half of those reporting each problem stated that they experienced it more frequently in 2008 compared to 2007 with the remaining respondents reporting each problem about "the same" frequency in 2008 as 2007. For example, of the $34 \%$ of respondents who reported that they delayed refilling a prescription in 2008 because they could not afford it, nearly half of them (17\% of all respondents) reported experiencing that problem more frequently in 2008 than in 2007. Overall, more than one in five respondents reported some form of CRN that was more frequent in 2008 than the year before. Among respondents aged 40-64, 25\% reported CRN that had worsened in 2008.

\section{Cost-related non-adherence and medication-financial hardships across employment groups}

Among respondents aged 40-64, medication-cost problems were prevalent across employment groups (Table 3 ). Nearly half (48\%) of respondents within this age category who were employed and $66 \%$ of those who were looking for a job reported some form of CRN. Other medication

Table 2 Adjusted* percentage of respondents reporting medication-cost problems in 2008 and reporting an increased frequency of cost problems in 2008 compared to 2007

\begin{tabular}{|c|c|c|c|c|c|c|}
\hline & \multicolumn{2}{|c|}{$\begin{array}{l}\text { All ages } \\
(N=27,302)\end{array}$} & \multicolumn{2}{|c|}{$\begin{array}{l}40-64 \\
(N=17,787)\end{array}$} & \multicolumn{2}{|c|}{$\begin{array}{l}65+ \\
(9,515) \\
\end{array}$} \\
\hline & 2008 & Increase & 2008 & Increase & 2008 & Increase \\
\hline Any cost-related non-adherence & $44.2 \%$ & $21.4 \%$ & $49.6 \%$ & $24.8 \%$ & $30.3 \%$ & $12.6 \%$ \\
\hline Delayed filling & 34.3 & 16.5 & 39.8 & 19.6 & 20.0 & 8.5 \\
\hline Split or took fewer pills & 33.9 & 15.0 & 38.0 & 17.7 & 23.2 & 8.0 \\
\hline Did not fill a new Rx at all & 24.0 & 10.4 & 28.5 & 12.5 & 12.5 & 4.8 \\
\hline Stopped taking Rx altogether & 18.7 & 8.3 & 22.3 & 10.0 & 9.4 & 3.8 \\
\hline Any other financial hardships & 51.2 & 27.0 & 54.9 & 30.1 & 41.5 & 19.1 \\
\hline Spent less on discretionary activities & 45.8 & 22.7 & 49.0 & 25.0 & 37.4 & 16.6 \\
\hline Spent less on necessities & 32.5 & 14.8 & 36.0 & 17.1 & 23.4 & 8.8 \\
\hline Increased credit card debt & 23.9 & 11.3 & 26.4 & 13.0 & 17.7 & 6.9 \\
\hline Borrowed from family or friends & 12.6 & 5.3 & 15.9 & 6.7 & 4.1 & 1.7 \\
\hline
\end{tabular}

Notes: Cell entries represent column percentages. "Increases" represent the proportion of all respondents reporting both CRN in 2008 and that the problem had become more frequent than in 2007. Estimates were calculated using sampling weights to approximate the proportion within the US non-institutionalized population aged 40 and older. *Estimates were adjusted for age and sex. All differences between age groups were statistically significant $(P<0.00 \mathrm{I})$.

Abbreviations: CRN, cost-related medication non-adherence; Rx, prescription. 
Table 3 Adjusted* percentage of respondents 40-64 years of age reporting medication-cost problems in 2008 and reporting an increased frequency of cost problems in 2008 compared to $2007(\mathrm{~N}=17,787)$

\begin{tabular}{|c|c|c|c|c|c|c|c|c|c|c|}
\hline & \multicolumn{2}{|c|}{ Employed (ref) } & \multicolumn{2}{|c|}{ Looking for work } & \multicolumn{2}{|c|}{ Not looking } & \multicolumn{2}{|c|}{ Retired } & \multicolumn{2}{|c|}{ Disabled } \\
\hline & 2008 & Increase & 2008 & Increase & 2008 & Increase & 2008 & Increase & 2008 & Increase \\
\hline Any cost-related non-adherence & $47.5 \%$ & $22.3 \%$ & $65.8 \%{ }^{\mathrm{a}}$ & $38.8 \%^{\mathrm{b}}$ & $52.0 \%{ }^{\mathrm{a}}$ & $25.7 \%^{\mathrm{b}}$ & $50.0 \%$ & $26.0 \%^{\mathrm{b}}$ & $57.2 \%$ & $26.9 \%$ \\
\hline Delayed filling & 37.2 & 17.5 & $56.2^{\mathrm{a}}$ & $29.8^{\mathrm{b}}$ & 40.4 & 19.6 & $40.8^{a}$ & 20.4 & $48.8^{\mathrm{a}}$ & 22.6 \\
\hline Split or took fewer pills & 36.4 & 15.7 & $49.7^{\mathrm{a}}$ & $25.8^{\mathrm{b}}$ & 39.8 & 18.1 & 36.8 & 18.8 & 41.7 & 19.0 \\
\hline Did not fill a new Rx at all & 25.2 & 10.4 & $40.7^{\mathrm{a}}$ & $21.1^{\mathrm{b}}$ & $30.7^{\mathrm{a}}$ & 12.0 & $30.2^{\mathrm{a}}$ & 14.3 & $35.5^{\mathrm{a}}$ & 10.4 \\
\hline Stopped taking $\mathrm{Rx}$ altogether & 19.4 & 8.2 & $34.3^{\mathrm{a}}$ & $19.6^{\mathrm{b}}$ & $23.8^{\mathrm{a}}$ & $10.2^{\mathrm{b}}$ & $24.5^{\mathrm{a}}$ & 10.6 & $27.0^{\mathrm{a}}$ & 11.0 \\
\hline Any other financial impact & 52.6 & 27.9 & $66.1^{\mathrm{a}}$ & $36.3^{b}$ & $56.4^{\mathrm{a}}$ & 29.9 & $58.6^{\mathrm{a}}$ & 33.8 & $63.8^{\mathrm{a}}$ & 34.4 \\
\hline Spent less on discretionary activities & 46.6 & 23.1 & $62.3^{\mathrm{a}}$ & $31.6^{\mathrm{b}}$ & 49.1 & 24.4 & $52.6^{\mathrm{a}}$ & $28.5^{\mathrm{b}}$ & $58.6^{\mathrm{a}}$ & 26.9 \\
\hline Spent less on necessities & 32.5 & 14.8 & $47.6^{\mathrm{a}}$ & $24.5^{\mathrm{b}}$ & $38.3^{\mathrm{a}}$ & 17.2 & $41.6^{\mathrm{a}}$ & $20.6^{\mathrm{b}}$ & $43.1^{\mathrm{a}}$ & 19.8 \\
\hline Increased credit card debt & 26.0 & 12.5 & 28.9 & 14.5 & 25.6 & 13.6 & 27.0 & 13.2 & 27.1 & 13.8 \\
\hline Borrowed from family and friends & 11.0 & 4.8 & $23.0^{\mathrm{a}}$ & $9.3^{b}$ & $20.3^{\mathrm{a}}$ & $6.9^{b}$ & $20.8^{a}$ & $8.3^{b}$ & $27.1^{a}$ & 7.9 \\
\hline
\end{tabular}

Notes: Cell entries represent column percentages. "Increases" represent the proportion of all respondents reporting both CRN in 2008 and that the problem had become more frequent than in 2007. Estimates were calculated using sampling weights to approximate the proportion within the US non-institutionalized population aged 40 and older. *Estimates were adjusted for age and sex; andicates that the 2008 proportion in that employment group was statistically different $(P<0.05)$ than the 2008 proportion for employed respondents; 'Indicates that the percentage of patients reporting an increase in CRN was statistically significantly different in that employment group relative to employed respondents. "Employed" respondents reported that they were employed full-time, part-time, or self-employed. The group of respondents "Not looking" for a job included respondents reporting that they were students or a stay-at-home "spouse, partner, husband, or wife".

Abbreviations: CRN, cost-related medication non-adherence; Rx, prescription.

financial hardships were also common. For example, $66 \%$ of those under 65 and looking for a job and $64 \%$ of those who were disabled reported they spent less on basic necessities or discretionary activities, increased their credit card debt burden, or borrowed money in order to pay for their prescription medications. More than half of those looking for a job who reported CRN in 2008 said that at least one of those hardships had worsened compared to 2007. For example, $50 \%$ of all employment seekers aged $40-64$ reported that they split, cut, or took fewer pills in order to make a prescription last longer in 2008, and $26 \%$ did so more frequently in 2008 than in 2007. Respondents who were looking for a job or disabled, seeking a job, or were retired were more likely than employed respondents to report medication-cost problems that had worsened since the beginning of the recession.

Overall rates of medication-cost problems were lower among respondents over the age of 65 (Table 4). However $26 \%$ of older adults reported that they were either working or looking for a job, and a large proportion of these individuals reported medication-cost hardships. For example, more than one-third of respondents who were over 65 and working reported some form of cost-related non-adherence in 2008, and $27 \%$ of working older adults reported that they split, cut, or took fewer pills in 2008 in order to make a prescription last longer. Problems were consistently more frequent among older adults who were working or looking for employment compared to those who were retired. A large proportion of older adults, particularly those who were either still working or looking for a job, reported that their medicationcost problems had worsened in 2008 compared to 2007 (and almost none reported that these problems had become less frequent, data not shown). For example, nearly half of the $23 \%$ of working older adults who reported that they delayed filling a prescription in 2008 because they could not afford it said that this had become more frequent than in 2007 before the financial crisis. Regardless of their employment status, a substantial number of older adults reported that in 2008 they more frequently experienced other financial impacts of their medication costs, such as spending less on necessities or discretionary activities, and increasing their debt burden.

\section{Auxiliary analysis: multiple chronic conditions and the "working poor"}

As noted in Table 1, most survey respondents had more than one chronic condition, and those with multiple illnesses may experience increased problems, both due to the increased burden of financial pressures and possibly the increased importance of medication use given their health status. Compared to the percentage of respondents reporting CRN among those with only one chronic disease (38\% reporting CRN), CRN reports increased systematically among those reporting two $(40 \%)$, three (45\%), or 4+ illnesses (59\%). Thirty percent of participants with four or more chronic conditions reported CRN that had worsened in 2008 compared to the prior year (compared to $16 \%$ of respondents with one diagnosis). Among respondents 40-64 years of age, $65 \%$ of those with four or more conditions reported CRN, with more than half of them reporting worsening problems in 2008 compared to the year before.

A total of 2,472 respondents reported household incomes $<\$ 35,000$ per year despite being employed. Because of 
Table 4 Adjusted* percentage of respondents 65+ years of age reporting medication-cost problems in 2008 and reporting an increased frequency of cost problems in 2008 compared to $2007(\mathrm{~N}=9,515)$

\begin{tabular}{|c|c|c|c|c|c|c|}
\hline & \multicolumn{2}{|c|}{ Retired (ref) } & \multicolumn{2}{|c|}{ Employed } & \multicolumn{2}{|c|}{ Looking for work } \\
\hline & 2008 & Increase & 2008 & Increase & 2008 & Increase \\
\hline Any cost-related non-adherence & $28.7 \%$ & $11.4 \%$ & $34.0 \% \mathrm{a}$ & $14.3 \%^{\mathrm{b}}$ & $43.2 \%$ & $17.9 \%$ \\
\hline Delayed filling & 18.1 & 7.3 & $23.2^{\mathrm{a}}$ & $9.9^{b}$ & $35.6^{\mathrm{a}}$ & 15.1 \\
\hline Split or took fewer pills & 22.0 & 7.3 & $26.5^{a}$ & 8.7 & 26.5 & 11.0 \\
\hline Did not fill a new Rx at all & 11.3 & 4.2 & 13.4 & 5.3 & $26.7^{\mathrm{a}}$ & 9.2 \\
\hline Stopped taking $\mathrm{Rx}$ altogether & 8.7 & 3.2 & 9.8 & 4.3 & 17.7 & 5.7 \\
\hline Any other financial impact & 39.9 & 17.5 & $45.3^{\mathrm{a}}$ & $21.7^{\mathrm{b}}$ & $59.3^{\mathrm{a}}$ & $35.5^{\mathrm{b}}$ \\
\hline Spent less on discretionary activities & 35.7 & 15.2 & $41.3^{\mathrm{a}}$ & $18.8^{\mathrm{b}}$ & $58.4^{\mathrm{a}}$ & 27.1 \\
\hline Spent less on necessities & 22.0 & 7.6 & 25.6 & $10.4^{\mathrm{b}}$ & 34.3 & 12.5 \\
\hline Increased credit card debt & 16.2 & 5.7 & $21.6^{\mathrm{a}}$ & $9.1^{\mathrm{b}}$ & 29.3 & 13.9 \\
\hline Borrowed from family and friends & 3.7 & 1.4 & 3.7 & 1.4 & 12.3 & $11.0^{\mathrm{b}}$ \\
\hline
\end{tabular}

Notes: Cell entries represent column percentages. "Increases" represent the proportion of all respondents reporting both CRN in 2008 and that the problem had become more frequent than in 2007. *Estimates were calculated using sampling weights to approximate the proportion within the US non-institutionalized population aged 40 and older. Estimates were adjusted for age and sex; andicates that the 2008 proportion in that employment group was statistically different $(P<0.05)$ than the 2008 proportion for retired respondents; 'Indicates that the percent of patients reporting an increase in CRN was statistically significantly different in that employment group relative to retired respondents. "Employed" respondents reported that they were employed full-time, part-time, or self-employed. "Retired" respondents included those who reported that they were unemployed but not looking for work, students, stay-at-home partners, or disabled and unable to work.

Abbreviations: CRN, cost-related medication non-adherence; Rx, prescription.

their limited resources and their higher likelihood of being uninsured, these "working poor" respondents represent an important subgroup. Two-thirds of this subsample $(66 \%)$ reported CRN in 2008, and 70\% reported other financial pressures due to their medication costs. Among those aged $40-64,70 \%$ of lower-income employed respondents reported CRN. Nearly one-third of the overall group of lower-income employed respondents reported CRN problems that had worsened in 2008 relative to the prior year.

\section{Discussion}

The results of this study provide evidence of a substantial increase in medication-cost problems associated with the recent economic recession. Madden and colleagues found that $8.6 \%$ of elderly Medicare beneficiaries in 2006 reported some cost-related medication non-adherence, and 5\% reported spending less that year on basic needs. ${ }^{9}$ Depending on their employment status, $11 \%-27 \%$ of those in the current study aged 65 or older said that they delayed filling a prescription in 2008 because they could not afford it, and 4-5 times as many older adults in the current study reported cutting back on basic needs compared to respondents in the Madden study. These relatively high rates of medication-cost problems in the current study relative to Madden's study may reflect the greater illness severity of the current sample based on their chronic illnesses and/or increases in financial pressures on older adults due to the financial crises - and despite the availability of Part $\mathrm{D}$ benefits.

Because of the high unemployment rates associated with the current economic downturn and the difficulty unemployed people have obtaining health insurance in the US, it may not be surprising that we found a high prevalence of medicationcost problems among respondents who were unemployed and looking for work or who were disabled. Nevertheless, it is important to point out that rates of medication-cost problems were high even among respondents who were working. A 2007 Commonwealth Fund survey showed that 24\% of respondents with employer-based private health insurance did not fill a prescription due to cost problems, and a more recent survey found that increasing numbers of middle-income Americans spent at least $10 \%$ of their income on out-ofpocket healthcare costs and premiums. ${ }^{32,33}$ Unfortunately, unemployment rates continued to climb between the time of this survey and the end of 2010, and the findings are at least as salient today as they were three years ago. As the current recession recedes and employment rates improve, we may see relative improvements in CRN. However, without significant health insurance reform, current trends toward less generous benefit packages could mean that negative impacts from out-of-pocket medication costs may remain common despite decreases in the unemployment rate.

As in many prior studies, ${ }^{15}$ these data suggest that rates of CRN are particularly high among chronically ill patients under the age of 65 who are ineligible for Part D coverage. Lower rates of CRN among older adults were reported in studies even before the Part D benefit was enacted, suggesting that factors such as greater overall financial assets and a higher priority placed on medication-taking also play roles in older patients' willingness to pay for prescription medications in the context of out-of-pocket cost pressures. The associations between age and CRN suggested by the current study probably underestimate the actual age effects, since on average, older adults take more 
medications and therefore face higher cost pressures. Political pressure to pass Part D as well as the ongoing debates about health care reform have largely de-emphasized these high rates of CRN among working-age adults or their potential consequences for rates of costly complications, morbidity, and preventable death. Given downward pressures on private insurance coverage, increasing rates of chronic disease, ongoing problems in the job market, and rising copayment rates, CRN among adults who are not eligible for Medicare should be continuously monitored and addressed.

Although this study used a large sample and provides some of the most recent information available about the impacts of prescription-drug costs on patients with chronic diseases, it has several important limitations. Respondents self-reported their perceptions about increases in medication-cost problems between 2007 and 2008. While this coincides directly with the onset of the financial crisis, other factors, such as illness progression or changes in insurance coverage unrelated to the recession, may have contributed to respondents' greater cost-related medication problems over time. Medication cost pressures were reported taking the patient's entire regimen into account, and as a result we cannot determine whether increases over time reflected more expensive prescriptions, a greater overall number of prescriptions, or costs within specific therapeutic classes. This study was conducted over the Internet. Only $53 \%$ of those screened completed the survey, and overwhelmingly, respondents were white. As a result, generalizability to the broader population should be made with caution. Nevertheless, estimates were relatively consistent with studies conducted using other survey methods, and sampling weights were used to correct for potential selection biases. To the extent that such biases exist, we would expect that individuals less comfortable using the Internet and those from racial/ethnic minority groups (particularly African-American and Hispanic patients) would tend to have less financial resources and therefore would be affected even more by the economic recession than what were suggested in this survey. Moreover, rates of medication underuse due to cost problems may be underestimated since patients who did not receive a prescription because they told their doctor they could not afford it were not identified in this study. Potential Medicare Part D beneficiaries who were aged less than 65 and reported that they were disabled and unable to work were not examined separately because data were not available on whether they met requirements for Part D or Medicaid coverage. If those potential respondents could have been identified, we assume that the relatively high rates of medication-cost problems would be even higher among the subset of disabled working-age Americans who do not have access to Part D or Medicaid coverage. Ideally, selfreports of medication cost problems are linkable to other, objective measures of patients' medication adherence, such as refill data from the Medicare Part D program. Of course, linking with Part D would only be possible for patients eligible for Part D coverage (eg, those $>65$ years of age or disabled). In the current study, linkage to refill/charge files was not possible. While this is a limitation with respect to understanding the specific prescription benefit characteristics and refilling consequences associated with cost-pressures, the broader population-based sampling frame of the current study provides a complement to research in which more comprehensive, linked datasets are possible.

Finally, as with any survey of medication-cost problems, results reflect respondents' assessment of their medicationtaking behaviors, which could be subject to reporting and recall biases. Some patients may under-report medication under-use due to social desirability bias or may over-report the problem because they attribute recent declines in their health status to this behavior. Nearly $95 \%$ of this sample was white non-Hispanic, making it impossible to examine variation in cost-related adherence problems across racial and ethnic groups. Other studies suggest that racial/ethnic minorities may respond differently to economic pressures from their pharmacotherapy. ${ }^{34,35}$ Future studies should oversample these groups to ensure that important disparities are identified for African-American and Hispanic people with chronic diseases.

In this study, we found severe problems with CRN that substantially impacted all groups with chronic illnesses, including those who were $>65$ years of age and eligible for Medicare Part D. Rates of CRN were especially high among adults aged 40-64, those who were unemployed, those with multiple chronic conditions, and those with lower-incomes despite being employed. Policies and strategies are needed that can minimize the impact of economic stresses on adherence to medications that are the most important for preventing major medical complications or premature mortality.

\section{Disclosure}

John Piette is a VA Research Career Scientist. Rodney Hayward, Ann Marie Rosland, and Maria Silveira also receive salary support from the VA. The Robert Wood Johnson Clinical Scholars Program and the Michigan Diabetes Research and Training Center, including the Measurement Core (NIH \#UL1RR024986) provide salary support for Rodney Hayward. Colleen A McHorney is the Senior Director of Merck's US Outcomes Research division. The survey was funded by Merck and Co, Inc. 


\section{References}

1. National Bureau of Economic Research. Determination of December 2007 peak in economic activity. Available from: http://www.nber.org/ cycles/dec2008.html. Accessed February 11, 2011.

2. Bureau of Labor Statistics. Labor force statistics from the Current Population Survey. Available from: http://www.bls.gov/cps/. Accessed February 11, 2011.

3. Dow Jones Industrial Average Learning Center. Dow historical timeline. Available from: http://www.djindexes.com/DJIA110/learning-center/. Accessed February 11, 2011.

4. RealtyTrac. December 2008 US foreclosure market report. Available from: http://www.realtytrac.com/ContentManagement/PressRelease. aspx?channelid=9\&ItemID=5807). Accessed February 11, 2011.

5. Soumerai SB, Pierre-Jacques M, Zhang F, et al. Cost-related medication nonadherence among elderly and disabled Medicare beneficiaries. Arch Intern Med. 2006;166:1829-1835.

6. Safran DG, Neuman P, Schoen C, et al. Prescription drug coverage and seniors: how well are states closing the gap? Health Aff. 2002: W253-W268.

7. Piette JD, Heisler M, Wagner TH. Cost-related medication underuse among chronically iII adults: the treatments people forgo, how often, and who is at risk. Am J Public Health. 2004;94:1782-1787.

8. Heisler M, Wagner T, Piette JD. Patient strategies to cope with high prescription medication costs: who is cutting back on necessities, increasing debt, or underusing medications? J Behav Med. 2005;28:43-51.

9. Madden JM, Graves AJ, Zhang F, et al. Cost-related medication nonadherence and spending on basic needs following implementation of Medicare Part D. JAMA. 2008;299:1922-1928.

10. Soumerai SB, Ross-Degnan D, Avorn J, McLaughlin TJ, Choodnovsky I. Effects of Medicaid drug-payment limits on admission to hospitals and nursing homes. $N$ Engl J Med. 1991;325:1072-1077.

11. Tamblyn R, Laprise R, Hanley JA, et al. Adverse events associated with prescription drug cost-sharing among poor and elderly persons. JAMA. 2001;285:421-429.

12. Goldman DP, Joyce GF, Zheng Y. Prescription drug cost sharing, associations with medication and medical utilization and spending and health. JAMA. 2007;298:61-69.

13. Federman AD, Adams AS, Ross-Degnan D, Soumerai SB, Ayanian JZ. Supplemental insurance and use of effective cardiovascular drugs among elderly Medicare beneficiaries with coronary heart disease. J Am Med Assoc. 2001;286:1732-1739.

14. Heisler M, Langa K, Eby E, Fendrick AM, Kabeto M, Piette JD. The health effects of restricting prescription medication use because of cost. Med Care. 2004;42:626-634.

15. Briesacher BA, Gurwitz JH, Soumerai SB. Patients at-risk for costrelated medication nonadherence: a review of the literature. J Gen Intern Med. 2007;22:864-871.

16. Zhang Y, Donohue JM, Lave JR, O'Donnell G, Newhouse JP. The effect of Medicare Part D on drug and medical spending. NEJM. 2009;361: 52-61.

17. Skarupski KA, Mendes de Leon CF, Barnes LL, Evans DA. Medicare Part D enrollment in a biracial community-based population of older adults. Gerontologist. 2009;49:828-838.

18. Zivin K, Kabeto MU, Kales HC, Langa KM. The effect of depression and cognitive impairment on enrollment in Medicare Part D. J Am Geriatr Soc. 2009;57:1433-1440.

Patient Preference and Adherence

\section{Publish your work in this journal}

Patient Preference and Adherence is an international, peer-reviewed, open access journal focusing on the growing importance of patient preference and adherence throughout the therapeutic continuum. Patient satisfaction, acceptability, quality of life, compliance, persistence and their role in developing new therapeutic modalities and compounds to
19. Pedan A, Lu J, Varasteh LT. Assessment of drug consumption patterns for Medicare Part D patients. Am J Manag Care. 2009;15:323-327.

20. Public Policy Institute. The impact of the financial crisis on older Americans: Research report. 2008. Available from: http:/www.aarp. org/money/budgeting-saving/info-12-2008/i19_crisis.html. Accessed February 11, 2011.

21. Kirking DM, Lee JA, Ellis JJ, Briesacher B, McKercher PL. Patientreported underuse of prescription medications: a comparison of nine surveys. Med Care Res Rev. 2006;63:427-446.

22. Wilson IB, Rogers WH, Chang H, Safran DG. Cost-related skipping of medications and other treatments among Medicare beneficiaries between 1998 and 2000. Results of a national study. J Gen Intern Med. 2005;20:715-720.

23. Reed M, Brand R, Newhouse JP, Selby JV, Hsu J. Coping with prescription drug cost sharing: knowledge, adherence, and financial burden. Health Serv Res. 2008;43:785-797.

24. Rector TS, Venus PJ. Do drug benefits help Medicare beneficiaries afford prescribed drugs? Health Aff. 2004;23:213-222.

25. Klein D, Turvey C, Wallace R. Elders who delay medication because of cost: health insurance, demographic, health, and financial correlates. Gerontologist. 2004;44:779-787.

26. Mojtabai R, Olfson M. Medication costs, adherence, and health outcomes among Medicare beneficiaries. Health Aff. 2003;22:220-229.

27. Ranji UR, Wyn R, Salganicoff A, Yu H. Role of health insurance coverage in women's access to prescription medicines. Womens Health Issues. 2007; 17:360-366.

28. Tseng CW, Dudley RA, Brook RH, et al. Elderly patients' preferences and experiences with providers in managing their drug costs. $\mathrm{J} \mathrm{Am}$ Geriatr Soc. 2007;55:1974-1980.

29. Piette JD, Heisler M, Wagner TH. Problems paying out-of-pocket medication costs among older adults with diabetes. Diabetes Care. 2004;27:384-391.

30. Kaiser Family Foundation. Views on prescription drugs and the pharmaceutical industry. April 2008. Available from: http://www.kff. org/spotlight/rxdrugs/index.cfm. Accessed February 11, 2011.

31. DeNavas-Walt C, Proctor BD, Smith JC. Income, poverty, and health insurance coverage in the United States: 2007. US Government Printing Office: Washington, DC; 2008.

32. The Commonwealth Fund. Failure to protect: why the individual insurance market is not a viable option for most US families. 2009. Available from: http://www.commonwealthfund.org/Content/Publications/IssueBriefs/2009/Jul/Failure-to-Protect.aspx. Accessed February 11, 2011.

33. Collins SR, Kriss JL, Doty MM, Rustgi SD. Losing ground: How the loss of adequate health insurance is burdening working families: Findings from the Commonwealth Fund Biennial Health Insurance Surveys, 2001-2007. August 2008. Available from: http://www. commonwealthfund.org/usr_doc/Collins_losinggroundbiennialsurvey 2007_1163.pdf?section=4039. Accessed February 11, 2011.

34. Piette JD, Heisler M, Harand A, Juip M. Beliefs about prescription medications among patients with diabetes: variation across racial groups and the influences on cost-related medication underuse. J Health Care Poor Underserved. 2010;21:349-361.

35. Tseng CW, Tierney E, Gerzoff B, Piette JD, Mangione CM. Race/ ethnicity and economic differences in cost-related medication underuse among insured adults with diabetes: the Translating Research Into Action for Diabetes Study. Diabetes Care. 2008;31:261-266.

optimize clinical outcomes for existing disease states are major areas of interest. This journal has been accepted for indexing on PubMed Central. The manuscript management system is completely online and includes a very quick and fair peer-review system. Visit http://www.dovepress.com/ testimonials.php to read real quotes from published authors. 